\title{
DIGITAL PLATFORMS AND ANTITRUST
}

\author{
GEOFFREY PARKER, GEORGIOS PETROPOULOS AND MARSHALL VAN ALSTYNE
}

Digital platforms are at the heart of online economic activity, connecting multisided markets of producers and consumers of various goods and services. Their market power and their privileged ecosystem positions raise concerns that they may engage in anti-competitive practices that reduce innovation and consumer welfare. This paper deals with the role of market competition and regulation in addressing these concerns. Traditional (ex-post) antitrust intervention will be less effective in markets driven by network effects unless it is combined with a proper (ex-ante) regulatory framework. Antitrust tools should focus on value creation and its distribution before focusing on competition. The scope of regulatory intervention should satisfy three criteria: i) value creation from operation of the platforms does not decrease due to the policy intervention; in particular, interventions should not reduce network effects; ii) allocative efficiency is based on distributing the value created in a fair way among market participants e.g. use of the Shapley Value. Fair and transparent rules must govern the platform ecosystem; iii) dynamic efficiency and competition ensure that incentives for market misconduct and anticompetitive strategies such as artificial entry barriers are eliminated. Market interventions that target a firm's market power should ideally retain value creation while also encouraging small firm entry and innovation. Data has a central role in online markets. Value creation is reinforced through a recursive a data capture and data deployment feedback loop which is enabled by machine learning technologies. A regulatory intervention that facilitates data sharing mechanisms, such that data will not only confer value to market leaders but also to their competitors to the benefit of consumers, is crucial for creating more competitive and innovative digital markets.

Keywords: Antitrust, regulation, digital platforms, data sharing JEL Classifications: K21, L40, L41, L43, L51, L86

Geoffrey Parker is a Professor at Dartmouth College

Georgios Petropoulos (georgios.petropoulos@bruegel.org) is a Research Fellow at Bruegel and a Research Fellow at MIT Sloan School of Management

Marshall Van Alstyne is a professor at Questrom School of Business (Boston University) and MIT Sloan School of Management

Georgios Petropoulos gratefully acknowledges financial support from the European Union's Horizon 2020 research and innovation programme under the Marie Sklodowska-Curie grant agreement No. 799093.

This paper was finalised in May 2020. It has been selected as a chapter contribution for the forthcoming Oxford Handbook of Transnational Economic Governance, edited by Eric Brousseau and Jean-Michel Glachant. 


\section{Introduction}

Digital platforms are proliferating in many countries and across numerous sectors of the economy. They frequently launch by matching two sides of a market (typically supply and demand), but often add additional types of users and are thus described as multi-sided platforms ${ }^{1}$. Because of rapid advances in ICT (information and communications technologies), platforms have lower costs than previous market forms and achieve scale that can create significant value for the interacting sides of their markets. We assert that they are a new way of addressing the fundamental problem of economic organisation: how to co-ordinate supply and demand in the absence of complete information. More specifically, through data collection, analysis, and aggregation they reduce the information asymmetries that can give rise to market failures (eg adverse selection and moral hazard) and distort trade (Akerlof, 1970).

In other words, platforms can be described as digital resources that enable efficient interactions between external producers, content providers, developers, and consumers that lead to value creation from (online or even offline) trade (Parker et al, 2016; Constantinides 2018). To do that, i) they adopt open digital infrastructures that allow multiple stakeholders to orchestrate their service and content needs; ii) they establish governance rules and invest in governance enforcement mechanisms that seek to balance platform control with the necessary incentives for platform participants to engage with the platform and generate value for one another (Constantinides et al, 2018). Platforms need to have in place an effective and fair dispute resolution system that corrects trade distortions in a timely manner.

Broadly we can distinguish between two groups of platforms:

- Aggregators are platforms that provide some valuable service to their users in addition to their interaction with external producers that they facilitate. For example, search engines like Google and Microsoft's Bing allow their users to reach a vast quantity of information. To do so, they invest in the effort of 'crawling' the Internet in order to catalogue and organise information resources. Users who patronise these search engines also see external producers' (eg advertisers) products and services. In most cases, online search is provided through such platforms at zero price and the search platforms monetise their operations by charging advertisers a price per user interaction that is realised through a generalised $k$-th price auction for the allocation of $k$ advertising slots per

\footnotetext{
${ }^{1}$ There is a large and growing literature on multi-sided platforms. See for example, Gawer and Cusumano (2002), Hagiu and Wright (2015), Parker and Van Alstyne (2018), Adner, Puranam and Zhu (2019).
} 
search keyword. Social media platforms like Facebook and Twitter are another example of this category. Users receive value through non-monetary interactions with their friends and influencers but, at the same time, they are invited to get in touch with advertisers through the personalised promoted content these platforms project to their users.

- Marketplaces are platforms that have as a primary objective to create efficient matches between consumers and suppliers of goods. Online marketplaces of goods and services such as eBay, Uber and Booking.com facilitate the matching between third parties in an efficient way through data collection, analytics, and techniques that reveal their users' preferences. In this category, there are also platforms that manufacture and sell their own products and services. Amazon Marketplace, Apple iTunes, and Google Play are examples of this subcategory.

An important concept to understand the rapid growth of platforms relative to incumbent firms is the "inverted firm" structure (Parker et al, 2017, 2018). The basic premise of the argument is that firms have long had a fundamental choice to organise internally as hierarchies or externally using markets (Williamson, 1973). Large firms have scale advantages, market access advantages, R\&D advantages that small players do not. Von Hayek (1945) provides one answer for why open markets might ever be more efficient than vertical integration. The answer is based in the idea that knowledge that is distributed in time and space such that external participants might use that knowledge to create value in ways that employees never could. Similarly, a lead user can combine their knowledge of private problems in ways that a focal firm would not have access to.

The rapid growth of the internet has allowed the large-scale aggregation of small scale network effects, that is, the phenomenon where systems become more valuable to users as a function of the number of users (see David, 1985; Katz and Shapiro, 1985; Varian and Shapiro, 1998). For example, an Alibaba product match, an Uber driver that attracts a rider, or a Google search that improves by use has a 'spillover' that is too small for an individual to capture or trade. Platforms, however, can capture and aggregate those positive spillovers and make it possible for system users to benefit.

Depending on the degree of a platform's openness, value creation can be primarily internal, primarily external, or some intermediate combination. Internal value creation is achieved through platforms' own production of output (products and services) that is directly valuable to their users. External value creation refers to external contributors such as app developers and external producers who can increase the user's benefit from participation in the platform. So, in the context of our analysis, value creation is defined as the total value that a platform can bring to its online ecosystem (the sum of platform's benefit, surplus to supply side users and app developers, and consumers surplus]. The 
allocation of value creation between the platform and its ecosystem of value adders defines the socalled inverted-firm problem, an important problem in platform strategy models (Parker et al, 2017, 2018). Many platforms have followed the path of external production and they harness some of their users as producers representing an external labour force that is not captured by the traditional labour statistics. Figure 1 depicts a selection of platforms and 'traditional' firms with similar market capitalization but with much different number of employees. This shows one consequence of platforms, as inverted firms, shifting production from inside to outside: the number of direct employees can fall dramatically relative to incumbent firms ${ }^{2}$.

Figure 1: Market capitalisation and employment for selected platforms and other firms

\begin{tabular}{|l|r|r|r|}
\hline \multicolumn{1}{|c|}{ Firm } & Start year & Employees & Mkt Cap (\$B) \\
\hline BMW & 1916 & 134,682 & 42.446 \\
\hline Uber & 2009 & 22,263 & 62.791 \\
\hline Marniott & 1927 & 176,000 & 46.35 \\
\hline Airbnb & 2008 & $12,736 *$ & $38 * * *$ \\
\hline Walt Disney & 1923 & 201,000 & 244.829 \\
\hline Facebook & 2004 & $44,942 * *$ & 598.041 \\
\hline IB:M & 1911 & 350,600 & 122.217 \\
\hline Salesforce & 1999 & $35,000 * *$ & 163.603 \\
\hline New York Times & 1851 & 4,320 & 5.319 \\
\hline Twitter & 2006 & $4,600 *$ & 25.604 \\
\hline
\end{tabular}

Source: Data on number of employees comes from Wikipedia and refers to 2018 except the cases below. Data on market capitalisation comes from the real time information of Yahoo Finance accessed on January 30, 2020. Exceptions: *Number of employees for Airbnb and twitter refers to 2019. **Number of employees from Facebook and Salesforce refers to 2020. ***Airbnb market capitalisation refers to 2018 and it is provided by Statista.

The emergence of dominant platforms with advantageous information about participants in the markets they control has drawn significant attention from regulators and economists. Such platforms are at the heart of online economic activity, connecting multi-sided markets of producers and consumers of various goods and services. Their market power, in combination with their privileged ecosystem position, raises concerns that they may engage in anti-competitive practices that reduce innovation and consumer welfare.

This paper deals with the role of antitrust in addressing these concerns. Digital markets can be particularly challenging for antitrust instruments as traditional tests of market power and dominance do not seem to work very well. First, a well-established market definition in some digital markets can

\footnotetext{
${ }^{2}$ Although the number of direct employees may be lower, the overall number of people in the system may actually increase.
} 
be problematic as market boundaries can be unclear. Because many online goods are offered for free, without any monetary price attached to them, it is very challenging to apply the small but significant and non-transitory increase in price (SSNIP) test to identify the relevant market (Hesse, 2007). This becomes even more challenging in the case of multi-sided platforms as the relevant market in such a case should look at all sides of the platform. In the absence of prices, product or service quality becomes an important variable of competition, especially in the markets of zero price goods. However, a good objective measure of quality in digital markets is still missing.

Second, digital markets are very dynamic. There is a small number of digital firms that have been involved in a large number of acquisitions of small firms and start-ups. While such mergers escape antitrust scrutiny when 'traditional' merger control rules are applied, there are concerns that, in some cases, proposed acquisitions are triggered by the strategic motives of large platforms to protect their market position from potential rivals. An open question is: When do mergers correspond with a wilful acquisition that does not reduce welfare and when do they serve strategic motives that raise entry barriers?

Third, the development of data analytics and machine learning has been proven revolutionary in monetising platforms' digital services and that has led to new market strategies. New theories of harm have been developed to address the complexity of the digital ecosystem, but they rarely have been tested in practice to assess their validity. At the same time, it is not clear how we can address anticompetitive strategies as the impact of potential remedies is unknown.

In what follows, we begin by discussing why we observe a rise of market power in digital markets and what the main theories of harm from high market concentration in platforms markets are. We then provide a critical evaluation of proposed solutions to antitrust problems related to digital platforms. Last but not least, we provide specific recommendations on how antitrust and regulation can address the theories of harms through the innovation of tools that can be used for this purpose. 


\section{Market power in digital markets: causes and implications}

The strategies of platforms have specific features that are relevant to market competition and policy:

- Multi-sidedness: The one side of the market can derive an added value from its interaction with the other side of the market (see, eg Rochet and Tirole, 2003; Parker and Van Alstyne, 2005; Armstrong, 2006; Rysman, 2009). This value can be either symmetric between the two sides (eg in the case of a marketplace where the primary objective is the trade of goods) or it may be the case that the one side derives more value from the interaction with the other leg in an aggregator where users place greater value on the platform's content and advertisers place higher value on interaction with users]. A platform may decide to subsidise one side of the market when its presence on the platform is very valuable to the other side. In aggregator platforms, advertising is the main source of business revenue. Since advertisers are attracted by the consumer users of the platform, platforms will often provide content for a very low price, or even for free, to consumers in order to attract them.

- Economies of scale: Digital goods and services are typically produced at a significant fixed cost but no or little variable cost (Varian, Farrell and Shapiro, 2004). In other words, the cost of production is much less than proportional to the number of customers served. Hence, once established, digital firms can grow quickly by expanding their operations to new users at minimum cost.

- Data-driven economies of scope: Machine learning and artificial intelligence has vastly improved the value of data for firms. By collecting, analyzing and aggregating large amounts of data, firms can improve product quality and expand their activities into new areas. Because machine learning yields better insights when it is trained on larger datasets, firms with access to large amounts of data can raise the quality of their services in ways that firms with restricted access to data cannot (see chapter 13 in Stucke and Grunes, 2016; Whittington and Hoofnagle, 2012; OECD, 2014; Gantz and Reinsel, 2011].

- Network effects: The user's value from participating in the platform can increase with the participation of other users in the platform. Network effects can be direct or indirect. Direct network effects are, for example, observed in social network platforms such as Facebook where the value users derive from the platform increases with the number of friends using it. Indirect network effects are, for example, observed in aggregators where the aggregation of data from additional users helps the platform to improve its product quality for all its participants. Network effects can go both directions. For example, in the Android ecosystem, the more users there are, the more 
attractive the platform for app developers and advertisers will be. This implies a greater variety and quality of products and services offered to the users. So, the platform becomes even more valuable and more users wish to join which in turn attracts more developers in a virtuous cycle.

The above characteristics of the platform ecosystem interact with each other in a way that in many cases creates more competition for the market and less competition within the market. Strong network effects combined with economies of scale and scope sharply increase the first mover advantage and diminish the benefit from entry by a second mover. The first mover can quickly increase its installed base, improve the quality of its services through the data-driven channel and further increase the number of its users at moderate cost of production. Given that digital markets have typically high fixed entry costs, competition shifts to which firm will be the first to enter a market. Once the firm has established itself, it is more difficult for a second mover to enter and compete in a profitable way.

On the one hand, this implies that firms have increased incentives to innovate and invest in new unexplored markets. On the other hand, they are discouraged from investing in markets where there is already a dominant digital player.

Even if market definition in two-sided markets and specifically in digital platform markets is, in principle, problematic, market tipping has created some super-platforms that have reached a scale that has allowed them to expand their operations in several closely-adjacent markets. Using the data generated knowledge from one market, and taking the advantage of their scale, they can expand their services to new markets, some of which have been areas of specialisation for 'traditional' firms. This expansion can be both vertical and horizontal. For example, Amazon evolved from an online marketplace to a physical one (acquisition of Whole Foods Market) or a producer of films and TV series (Amazon Prime Video). Google first provided the Android operating system for mobile phones and then entered the market for smartphone production. Some digital platforms like Facebook expanded their business to financial services and cryptocurrencies where information about people's preferences is important for providing high quality and well-tailored services to individuals.

With such expansion, big platforms have become a significant force of disruption in the economy. The disruption can have many market equilibrium outcomes with implications for competition and market power. Incumbents in non-digitalised sectors have incentives to innovate and adopt digital technologies in order to compete more efficiently with their market digital newcomers, to the benefit of consumers. On the other hand, it is still hard for them to compete with platforms that have both superior knowledge (data) and can take the advantage of their already established digital network. 
The 2019 UK Report of the Digital Competition Expert Panel, by combining data from different sources [eg StatCounter, Comscore, Plum Consulting] concludes that concentration is particularly prominent in the following digital markets:

- Online search, which is dominated by Google, with some competition from Microsoft Bing,

- Social media, dominated by Facebook and the services its owns, with some competition from Twitter and Snapchat,

- Digital advertising, dominated by Google and Facebook,

- Mobile app downloads, which is a duopoly between Apple and Google,

- Commerce through online marketplaces, where Amazon is a dominant platform, with some competition from eBay.

Empirical evidence suggests that the trend of increasing market power is not only a characteristic of digital markets, but of the economy as a whole. Loecker et al [2020] study the evolution of market power for the US economy since the 1950s. Based on firm-level data, they find that, while market power was more or less stable between 1955 and 1980, there has been a steady rise in market power since 1980 , from $21 \%$ above cost to $61 \%$ above cost in 2016 . In the same spirit, Diez et al (2018) study the evolution of mark-ups of publicly traded firms in 74 economies from 1980-2016 conclude that mark-ups have increased by an average of 39 percent since 1980.

The observed rise in market power since 1980 can be attributed to several factors. Most relevant to this chapter are the following:

- Lack of competition: higher concentration could reflect a decline in market competitiveness (Gutierrez and Philippon, 2017).

- Towards efficient production: Differences in productivity between firms may lead to a reallocation of demand toward the highest-productivity firms as goods become more substitutable (Autor et al, 2019).

- Increasing information intensity: The composition of economic output is moving toward products and services that are delivered digitally instead of physically (Barefoot et al, 2019, McAfee and Brynjolfsson, 2008).

The empirical trends are particularly prominent for digital markets according to Calligaris et al (2018). In particular, they assign an index of digital intensity to each sector which is based on sectoral tangible and intangible ICT investment, purchases of intermediate ICT goods and services and use of robots. 
They find that the increase in mark-ups from 2001-03 to 2013-14 is larger for the average firm in a digital-intensive sector than the average firm in the pool of nonintensive-digital sectors. So, there is a positive correlation between mark-ups and digitalised sectors which is stronger over time.

However, such findings should be viewed with some caution. First, how to measure markups is a topic of a current debate. For example, Philippon (2019) does not find an increase in mark-ups and concentration in the EU. He only points out a sharp increase of concentration in the US markets. At the same time, Traina (2018) criticises the way that markups are measured in the above-mentioned literature. Hall (2018) finds no evidence that mega-firm-intensive sectors have higher price/marginal cost markups, but he reports some evidence that markups grew in sectors with rising mega-firm intensity. The implications of increasing markups are also under debate. One implication is that this trend captures the increase in market concentration. But, it may instead refer to higher production efficiency, namely, declining marginal costs, especially in technology related or information intensive markets, which lead to increasing markups without necessarily any increase in prices. Our take on this is that the increase in concentration, especially in US markets, has been large enough that it is difficult to ignore. But, specific sectoral dimensions of this trend require further research to reach concrete policy implications.

\section{Market power in digital markets: main theories of harm}

Market power that is gained through an efficient competitive process is good news because it implies efficiency in the production process and high quality products and services. The winner of the competition for a given market is expected to be the most efficient firm to serve the market. When a dominant position is associated with maximisation of efficiency in production and value creation should be welcome. This is the reason why competition law does not consider a dominant market position to be anticompetitive or illegal. It only focuses on the cases in which market power is abused to protect or increase dominance by i] distorting allocative efficiency: whether the created value is distributed in a fair way among market participants or the dominant firm abuses its power in the expense of its competitors, external producers and consumers; ii) reducing dynamic efficiency: whether dominant platforms' strategies artificially raise barriers to its competitors or external suppliers to become more efficient and further increase the value creation to the benefit of consumers.

The theories of harm associated with market power and anticompetitive conduct have to do with three key market variables: price, quality, and innovation. High prices, low quality, and low investment on 
innovation that are not supported by the competitive equilibrium can lead to inefficiencies and harm consumers. Below, we provide the main theories of harm associated with digital platforms. Examining the validity of these theories in practice requires a case-by-case analysis.

\section{Excessive prices}

On the relationship between platforms and external producers, the economic literature has analysed how market power and network externalities can lead to harmful pricing strategies by platforms. They can be inclined to offer low or zero prices and high-quality services to consumers and charge excessive prices to the other side (eg advertisers, external producers). That in turn means that the other side will incur a higher cost to reach consumers and that will be reflected in the final prices of their products and services with negative implications for consumer welfare. Armstrong (2006) defines this as a competitive bottleneck: A platform, by attracting one side, exploits its market power over the other side by charging a monopoly price as it becomes the only channel that facilitates interaction between the two side. In this way, the platform gets the highest share of value creation while it becomes more difficult for competing platforms to stay in the business because they lack access to the most valuable side (consumers).

The question is, when is it less likely for the competitive bottleneck to arise as an equilibrium? The degree of multihoming at the platform level is an important factor. When at least some of the consumers simultaneously visit more than one platform, the competitive bottleneck equilibrium is less likely to arise (Beleflamme and Peitz, 2019, Bakos and Halaburda, 2020).

A particular strategy in the case of online marketplaces that has been found to be anticompetitive by multiple competition authorities in Europe ${ }^{3}$ is the most-favored (or price parity) clause (Ezrachi, 2015, Petropoulos, 2018). Under such (often long-term] contractual agreements, external suppliers commit to charge a price on the platform that is not higher than prices charged on other platforms (and retailers in general] where they supply products and services. Edelman and Wright (2015) show that when price parity clauses are defined too broadly, they have the potential of undermining the dynamics of competition and reducing consumer welfare. This can occur in two ways: i] Price parity clauses may limit competition between platforms on the level of the commissions they charge to suppliers. This can potentially lead to a higher commission charge to external producers and

\footnotetext{
${ }^{3}$ See for example the press releases by the Office of Fair Trading (OFT) on August 29, 2013, under the title "OFT Welcomes Amazon's Decision to End Price Parity Policy," and the German Competition Authority on November 26, 2013, under the title "Amazon Abandons Price Parity Clauses for Good.". See also COMP/C-2/39.847 that concerns Apple and its iBookstore.
} 
eventually to higher prices being charged to final consumers; ii) they may hinder entry into the market because they effectively lock all prices at the same level. For example, in the OFT's case against Expedia and Booking.com, the small online travel agency Skoosh.com complained that the clause raised barriers to entry and harmed Skoosh's ability to build a presence in the market, to the detriment of competition.

On the relationship between platforms, and digital firms in general, two classical problems of antitrust can become relevant: Price discrimination and algorithmic [tacit] collusion. On the former, digital firms, with data collection and analysis, can approximate with great accuracy their consumers' willingness to pay and employ personalised pricing strategies that leave them with only a moderate surplus (this is what Ezrachi and Stucke 2016 call behavioral price discrimination].

Algorithmic systems employed by digital firms to set prices for consumers can observe in real time not only demand conditions but also the pricing strategies of their competitors. In a repeated game theoretic approach this can lead to a very stable tacit collusive price equilibrium which by definition is above the competitive level. The high stability of collusion in this case is achieved because any deviation from the collusive equilibrium by one firm is immediately observed by the others which can react by adjusting prices to punish the deviator (in line with the grim-trigger strategies of Friedman, 1971). Calvano et al (2018) provide an experiment with pricing algorithms and run computer simulations which show that algorithms consistently learn to change prices above the competitive levels even when they do not communicate with each other. What is particularly challenging in this case is that tacit collusion is not illegal according to competition law. In practice, without the existence of hard evidence to prove conspiracy it is very hard to block such strategies.

It should be noted that, despite the intensive discussion in the antitrust community over the risk of collusive prices, only one antitrust case involving algorithmic pricing has been opened so far. It involves the adoption of specific pricing algorithms by online firms for the sale of certain posters sold through Amazon Marketplace in the United States, with the goal of coordinating changes to their respective prices. The case ended with a guilty plea ${ }^{4}$.

The European Commission's e-commerce sector inquiry found that price monitoring software is extensively used and can generate competition constraints:

\footnotetext{
${ }^{4}$ See US vs David Topkins, https://www.justice.gov/atr/case/us-v-david-topkins.
} 
- Retailers use software to monitor the prices of their competitors, and the majority of them consequently adjust their own prices to those of their competitors.

- Manufacturers use software monitoring practices to detect whether their retailers comply with the prices they recommend.

These practices imply that, indeed, firms learn about price fluctuations in their competitors' product in real time, frequently before such fluctuations are observed by potential consumers that shop online.

Pricing with algorithms that can observe prices of competitors at real time resembles the case of immediate-response oligopoly markets. A well-known example of such a market is the one of for commercial US airline bookings that led to the 1994 airline tariff publishing case (see Borenstein's chapter in Kowka and White, 1999). US airlines set up a central clearinghouse for the distribution of fare change information. On a daily basis, airlines sent new fare information to this clearinghouse as well as old fares to be removed and existing fares to be changed for given routes. In response to that, the clearinghouse produced a compilation of all industry fare change information and sent that computer file, which included thousands of fare changes, to a list of recipients (major airlines and computer reservation systems]. A usual practice was that airlines pre-announced fares before implementation. This allowed competitors to observe how prices would change and let them adjust their pricing behaviour before price changes were implemented. The remedy was to prevent airlines from pre-announcing fares.

Although the airline pricing structure resembles to some extent our case of competition with algorithms, we note that the remedy imposed on the airlines would likely not be effective for algorithmic pricing, because, price changes are now observed in real time and are not pre-announced. Any potential collusive equilibrium is therefore more likely to be tacit than explicit.

\section{Inferior quality}

By analysing user data in real time, platforms can determine users' emotional state and offer targeted sales. This includes creating incentives for users to spend more time on a platform to the exclusion of other activities. By enticing users to stay longer on a platform, the probability of interaction between two sides of the platform increase. However, as this interaction might be the product of an emotional manipulation, it can decrease consumer welfare (see final report from the Stigler Committee on digital platforms 2019]. 
In addition, the analysis of users' data can also lead to discrimination based on users' personal information (racial, ethnic origin, skin color, location), which can be perceived as leading to lower quality for specific demographic groups.

A more recent theory of harm has to do with data privacy (Economides and Lianos, 2019). In the Facebook/WhatsApp merger case, the European Commission emphasised that privacy policies constitute a non-price parameter of competition. The degradation of privacy policies could lead to a decrease in product quality. Since data collection and analysis is of vital importance in platform business, in their efforts to increase their market power and to remain as necessary gate keepers of their internet business, some platforms may be engaged in excessive data collection and manipulation thus reducing data protection and quality of service. In the more recent German Facebook case, for example, the Federal Cartel Office concluded that Facebook abused its market power by pooling data from third-party apps (including its own WhatsApp and Instagram systems) and that it expanded its online tracking to people who aren't members of the platform through Facebook 'like' or 'share' buttons.

It is important to understand that potential misuses of data that lead to lower quality of service may endure even if competition in the platform level increases. This is because such misuses are, in many cases, a hidden problem that is not observed by the users. This is analogous to security software where users do not have the expertise to evaluate whether a security package works or not (Anderson, 2001). In the latter case, firms can compete by cutting price but lowering costs via hidden quality reductions (eg provide protection against fewer types of attacks). In a similar way, when competition among platforms increases, this may result in lower (observable) prices for each platform's service, but it may also provide further incentives for a (unobserved) data exploitation to recover some of the profit loss due to the increase of competition and lower price equilibrium.

Focusing on the relationship between platforms with their business users, the European Commission (European Commission, 2018) has run a business survey which identified that business users may receive inferior quality services by some platforms with whom they interact (Figure 2). Some examples of typical responses by business users over the platforms' provision of quality issues that emerged from this survey are: sudden unilateral changed in the access terms and conditions, favouring own services, delisting and suspension of accounts, and so on. 
Figure 2: Overview of inferior quality problems related to business users

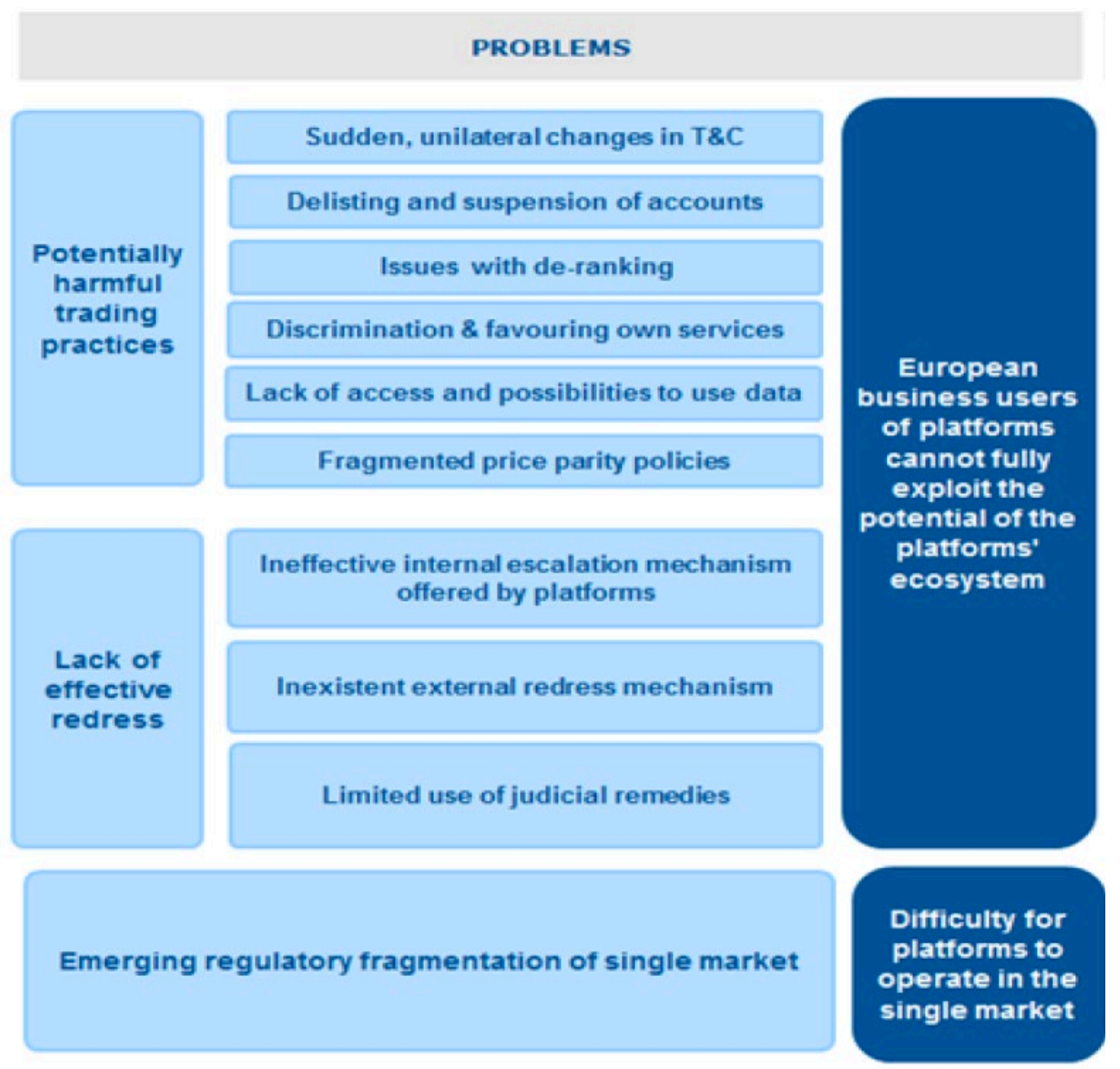

Source: European Commission (2018).

Platforms have control over framing consumer choices, policies for goods supplied through the platform, and technical standards. In many cases, they keep complete control over the user relationship as well as platform access rules. They therefore have incentives to avoid the threat of entry and disintermediation. Data can substantially help platforms to do that. They may not share critical information with their trading partners that could potentially lead to the threat of disintermediation, but this can also lead to forgone production efficiency gains. In some cases, this implies that trading partners are forced to operate without clarity over market conditions. Platforms may also provide complementary services by being present in the upstream market. Then, by adjusting the access policy of their upstream competitors they can enjoy further benefits through the promotion of their own upstream services to consumers. Strategies that platforms employ to achieve that include: exclusive contracts, biased recommendations (eg European Commission's Google 
Shopping case), bundling and technical incompatibilities (eg European Commission's Google Android case and Intel case). Such practices that are related with the vertical structure of digital markets can affect all the three key variables discussed above. The vertical integration of big platforms that provide services to upstream markets can generate an incentive problem that hurts small upstream competitors and may even lead to market foreclosure with detrimental welfare effects. However, as already discussed, the potential anticompetitive implications should be analysed in a case-by-case analysis, because they can also bring efficiency gains in trade and production.

\section{Reduced incentives for innovation}

The implications of market power on innovation has been a topic of active debate in academia. There is no consensus between endogenous growth models, agency models, and empirical evidence on whether market power reinforces or discourages innovation. Literature has focused on the impact of competition on firms' innovation incentives, defined as the difference in the profits a firm earns when it innovates and when it does not. This 'incentive-effect' of competition can be either positive or negative. On the one hand, firms that operate in a competitive market have incentives to innovate to escape from competition and enjoy higher market shares (the 'escape-competition' effect following Aghion et al (2005), which is a slightly modified version of the 'replacement effect' of Arrow 1962). On the other hand, firms that enjoy monopoly rents have higher incentives to innovate to protect their market position and discourage entry by potential competitors (the Schumpeterian effect, based on the notion of creative destruction introduced by Schumpeter, 1934). Most of the theoretical contributions have focused on the interaction between these two opposing forces for different market structures and characteristics of innovation.

In the case of platforms, the theory of harm in investments on innovation focuses on the fact that once the competition for the market phase has been completed and the winner has emerged, the latter has incentives to engage in anticompetitive practices to limit the threat for successful entry and innovation. But, by raising entry barriers, incentives for innovation decrease. Since innovation is a way to improve a firm's market position against its competitors, if the probability of entry by competitors is reduced through other practices that rely on market power, then innovation is less necessary to protect a market position.

But the story does not stop here. According to this theory of harm, incentives for innovation by small firms are also hurt. It is difficult for start-ups to find funds and convince investors to trust them in order to innovate if they compete (or try to enter] in a market with very established platform or if they 
compete in a platform's trading partner market but all the trading surplus is appropriated by the platform. A venture capital firm will not want to invest in a start-up that directly competes with a tech giant. It will also not want to invest in a start-up operating in a vertical market whose surplus is appropriated by the platform.

\section{Further theories of harm}

Platforms have two critical sets of information, information over competitors' offers in the upstream market where they also have their own shop (vertical integration) and potential competition by small firms that could potentially grow and become competitors. For the first set, platforms may have incentives to engage in predatory pricing to force upstream competitors to exit the market and at the same time expand their offerings and improve their quality to capture more demand.

For the second set, they may proceed with a 'killer' acquisition so that they will not face the threat of entry in the future. When a platform identifies a small entrant that is quite innovative and may threaten its market position in the future, it may be inclined to acquire it, not because of the extra value it will bring in the business, but because they want to avoid potential competition in the future. In digital markets, especially the ones dominated by a big platform, merger activity is quite intense. Big platforms frequently acquire smaller firms in the same or closely adjacent markets. Since one of the merged entities is small and without significant market power, such mergers in the most of cases escape the scrutiny of competition authorities. Such acquisitions can also have detrimental effects for the whole digital ecosystem in terms of investments and innovation. Kamepalli, Rajan and Zingales (2020) provide evidence that shows a decrease in investment in startups by venture capitalists after major acquisitions by Facebook and Google.

\section{Market power in digital markets: potential solutions}

In this section, we critically evaluate proposed solutions and we propose an avenue that could potentially solve many of the associated problems.

In the centre of our approach is data and its contribution to value creation. Data helps multi-sided platforms to better profile their customers and offer them higher quality services. In addition, through the aggregation of data, they can capture underlying trends in the ecosystem and further improve quality, controlling for exogenous factors. We expect that the amount and variety of data collected by 
platforms (which we will collectively call the size of the data sample) to be positively related with value creation. Factors determining the relationship between data and value creation the types of data collected given the considered application. Data is the key input in algorithmic systems. It is of vital importance for training algorithms to become more efficient in their tasks. The relationship between value creation and data also depends on the specific market and the advancement of sectoral-specific applications of machine learning and artificial intelligence. Bajari et al (2019) look at the effect of increasing the size of data sample on accuracy in the context of Amazon's retail demand forecasting system. They feed their statistical models with data along two dimensions: the number of products $\mathrm{N}$ in the same category and the number of periods $T$ for which a particular product has been on sale. They find that additional data on previous forecasts and the subsequent realisation of retail quantities improves the accuracy of retail forecasts for a particular product, though at a diminishing rate.

However, diminishing returns are not necessarily the case when we look at the impact of an increase in the size of the data sample on the recommendation quality in a search engine environment. Schaefer et al (2018) illustrate that additional data from previous searches on the same keyword tends to improve the quality of search results. If initial quality is not high, then the increase in the size of the data sample can have a greater impact than diminishing returns might suggest. Moreover, the study concludes that the type of data also matters. Personalised data is the most valuable for the specific application. Closely tracking the activities of few users and accumulating their data over time may bring greater value than collecting non-personalised data that covers a large number of users. We build on these insights as follows: Figure 3 presents an example of an algorithm that performs a specific task and in which data exhibits sigmoid returns to scale. The extra value of data depends on the size of the data sample already collected and analysed.

\section{Figure 3: Value creation when data is used for a specific purpose}

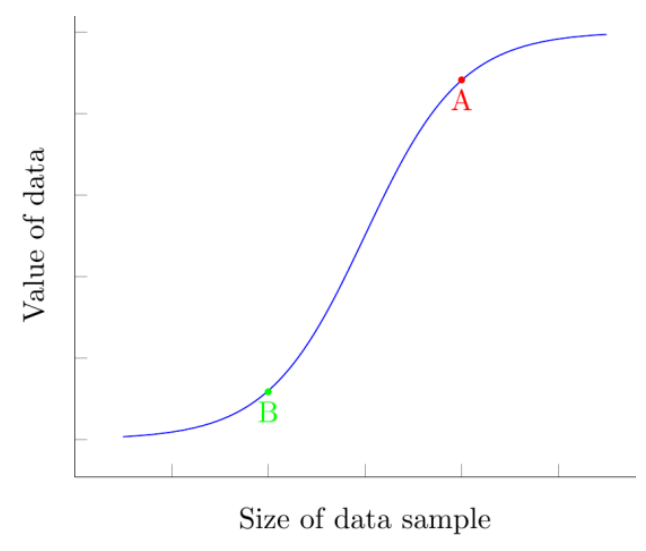

Source: Bruegel. 
However, note that data can also be re-purposed, thus bringing additional value. For example, in cases where algorithms wish to capture consumer preferences that shift frequently, the size of the data sample can help firms to quickly identify these shifts and adjust their digital services accordingly. Moreover, the data sample in one market, when it is sufficiently large, can be helpful when entering a closely adjacent market. Overall, when data is used only in algorithmic systems with a specific task, it is more likely to exhibit diminishing returns to scale. But, when it is used in additional applications or in capturing dynamic trends, then it can also exhibit increasing returns to scale. Further empirical research is needed to assess the exact magnitude of economies of scale in such cases.

\section{Proposed solutions}

One of the most widely discussed solutions has to do with breaking up the big platforms. If the break up is horizontal and involves breaking a monopoly platform to two (or more) within the same market, then, as Figure 3 suggests, value created can decrease. Consider that the monopoly platform before the break has accumulated a lot of training data and it is at point $A$. If the breakup has as an outcome the creation of two equivalent platforms at point $B$, then the new policy can significantly decreased the value created.

Consider now an alternative scenario: That the break up allows each of the firms to use the same amount of data as before the break up (both platforms are at point A), thus cloning the platform. Then, there is no loss of value in the short-run, but this equilibrium may be unstable in the long-run. Since both platforms offer the same services, under the presence of network externalities and economies of scale, competition for the market ensues. The first platform that manages to increase its users will start growing and, in the end, there might again be a dominant platform. Competition between MySpace and Facebook was at one time very intense but Facebook emerged as the winner and became a dominant platform in social networks. The growth of platforms such as Twitter and Linkedln can be explained by the fact that they offered sufficiently differentiated services and found room to increase their market position. So, a horizontal break up may not work as intended because it can lead to efficiency losses and may only reduce market power in the short-run.

We could also consider a vertical break up, similar to Senator E. Warren's proposal. As already discussed, many platforms have extended their operations along the vertical line. They not only facilitate interactions between consumers and external producers but they also produce upstream products and services themselves. Vertical integration in this case can provide an information advantage for the platform's upstream subsidiary over demand and the strategies of upstream 
competitors. Vertical integration can generate extra value because the upstream provider has better information about what consumers want and it can also solve the double marginalisation problem. Nevertheless, it may provide incentives for the platform to preferentially treat its own subsidiary at the expense of external suppliers. A break up could remove such anticompetitive incentives. But, it could also reduce the value creation from the production by the upstream subsidiary. What we argue below is that a well-designed regulatory framework that eliminates the risk of mistreatment of the external suppliers and facilitates symmetric information sharing at the upstream level could work better because at the same time value creation would not decrease and a level playing field in the upstream market can be restored.

Some big tech platforms are present in multiple closely adjacent, parallel markets. A break up could also occur by restricting each platform to operate in only one market. There are two challenges with this approach. First, in some cases, it is very difficult to find a clear separating line between different digital markets. Second, the data and information in one market can have a strong positive spillover effect in another one that is closely related. Thus, a break up can again lead to a reduction in the value creation.

Another solution that received extensive coverage is to treat data as labour (Posner and Weyl, 2018): Data has an immense value for platforms. It can be used to train algorithms and improve products. As a result, they argue that platforms should provide a fair payment to each individual for using their data. In other words, the use of these platforms should be viewed as a labour contract for each individual. This proposal calls for the formation of independent data labour unions which will regulate the price individuals will be paid and will manage the transaction. Since individuals have both limited time and attention, unions will need to solve the allocation problem by setting prices in an appropriate way. Unions should also set lower prices (or zero prices) for small entrant platforms to counterbalance network effects, data value effects, and economies to scale.

Obviously, direct monetary transfers to users could increase consumer surplus. In fact, in the case of Facebook, in a static environment, Benzell and Collis (2019) find that this increase will be around $24 \%$. But, there are a number of reasons that this approach may not work, at least, at the current stage where a formal model for its implementation is missing. First, it is empirically unclear whether the users of the platforms derive lower value than the value the platforms derive from them. In the former case, any monetary transfers from platforms to consumers may have negative dynamic effects on incentives for investments on innovation and improvement of services. So, such transfers can be welfare reducing in the long-run. Second, it is very difficult to imagine the formation of new state 
independent data unions that will have the power to impose the market prices for data. History has shown that labour unions in many cases lack bargaining power lespecially in work provided through digital platforms) and that prices can only be restricted by formal (state) regulatory intervention. As we argue below, it is the regulatory framework that will be put in place that can be instrumental in incentivising data sharing mechanisms with benefits for individuals. Finally, we should not ignore that, in many applications, it is not the individual data but its aggregation that significantly increases value creation.

There are also proposals that move away from competition by considering other instruments that can apply. For example, taxation of digital platforms has been proposed as a way to redistribute in a better way the value created in platform ecosystems. While such a tax can have important redistributive implications, it does not seem so promising in solving the theories of harm associated with market power. We also need to put in place other instruments that can lead us directly to a more efficient dynamic market competition.

\section{The way forward}

Our ${ }^{5}$ main takeaway is that traditional antitrust intervention (typically taking place ex-post) will be less effective in markets driven by network effects unless it is combined with a proper regulatory framework (which is set ex-ante). Hence, instead of discussing whether antitrust should change its legal standards and principles as proposed by the New Brandeis approach (as well as the consumer welfare criterion as it has been suggested by legal scholars like Steinbaum and Stucke, forthcoming] to address concerns of platform market power, we propose an alternative as follows. The rest of this section is based on our forthcoming research where we develop the details of our proposal (Parker, Petropoulos and Van Alstyne, 2020). In the remainder of this piece, we summarise its main features.

Antitrust tools should focus on value creation before focusing on competition. The scope of regulatory intervention should satisfy the following three criteria:

i) Value creation from operation of a platform does not decrease because of the policy intervention; in particular, interventions should not reduce network effects.

ii) Allocative efficiency is based on distributing the value created in a fair way among market participants e.g. through use of the Shapley Value. Fair and transparent rules must govern the platform ecosystem.

\footnotetext{
${ }^{5}$ With the exception of the merger control instrument.
} 
iii) Dynamic efficiency and competition ensure that incentives for market misconduct and anticompetitive strategies such as artificial entry barriers are eliminated.

This approach requires a harmonic relationship between antitrust and regulation with several implications.

The first one has to do with the definition of the relevant market. It can become extremely difficult to define the market, especially in the case of the provision of free goods. Free goods platforms typically bundle complements so that interactions across search, mapping, email, and home devices create network effects. Instead of examining markets, it may be better to focus on the provision of the specific service and the value they generate to the digital ecosystem. In this way, we can be more concrete in defining substitutable services and assess the level of competition for each particular service.

In fact, Brynjolfsson and Collis (2019) provide a new methodology on how to assess the substitutability of free goods in an incentive compatible way at the service level. They use digital survey techniques to run massive online choice experiments examining the preferences of hundreds of thousands of consumers. They estimate the consumer surplus for a great variety of goods, including the ones that are offered at zero price. They find that the median compensation Facebook users were willing to accept to give up the service for one month was $\$ 48$. On this basis they estimate that US consumers have derived $\$ 231$ billion in value from Facebook since 2004 (Brynjolfsson et al, 2019).

Such an experiment can be easily be extended by assessing what would have been the choice of a user if one of the platforms would not have been available. Users' choices in such a case can assess the degree of substitutability between platforms. If such an approach is combined with an assessment of the substitutability on the other side of the market (eg advertising), which typically exhibits positive prices and where it is therefore easier to apply standard antitrust methodology, we can get a more comprehensive picture over the competitive pressure for the provision of that service.

On the side of antitrust and its only ex-ante instrument, merger control, authorities should develop a more forward looking perspective when they evaluate merger cases, especially the ones that raise the suspicion of a killer acquisition. For this they need to assess what the potential competition effect is if the merger is not allowed. Would WhatsApp become a direct competitor of Facebook if the merger was not allowed? If the answer is likely to be yes, then the merger may decrease consumer welfare as it restricts potential competition that could lead to lower prices and higher quality and therefore be prevented. But, in practice, it is very challenging to assess potential competition. One avenue that can 
be helpful with this respect could be to measure the substitutability of platforms' services during the merger evaluation (which could be based on the methodology suggested in the previous paragraph). That can take place with the employment of surveys and online questionnaires and experiments that ask users (through a design that satisfied incentive compatibility) about what platforms would attract their attention if a specific platform was no longer available. For the impact of the merger on concentration in the other side of the market where positive prices are used to clear the market, traditional tools in merger simulation can be applied. Hence, in this way we can assess the impact of a proposed merger. Closely substitutable platforms can potentially lead to a competitive equilibrium with direct welfare implications for the merger case.

At the same time, we should strengthen ex-post evaluation of merger cases and be ready to impose remedies that are contingent to specific future outcomes. If it becomes clear that the remedies attached to the past approval of a merger do not have the desired effects, there should be flexibility so that such remedies could be modified accordingly. It would be helpful if remedies are periodically reviewed to assess whether they have the desired effect and are updated accordingly. The specific targets in terms of the welfare impact of a merger should be clearly communicated at the time of the approval of the merger. Remedies should be flexible to change in order to ensure that the specific targets are reached, if needed. Last but not least, particular attention should be paid to the details of the merger deal (eg price of the takeover), as it may signal strategic motives, as well as at the impact of the merger on the incentives and ability of firms to innovate. Mergers that are classified as killer acquisitions are more likely to have negative impact on innovation (Kamepalli, Rajan and Zingales, 2020).

Regardless of the specific merger cases that are being evaluated, the option of well targeted market surveys at different points of time could be very useful. They could provide a better understanding of the substitutability between alternative options and how they evolve over time, even if they do not operate in the same markets.

With respect to the second instrument of antitrust on price fixing agreements and tacit collusion, the empirical challenge is that it is very difficult for the authorities to assess what the competitive price is in real time. Algorithms have accurate information at any point of time on demand conditions and the selling strategies of competitors.

The approach with respect to tacit collusion should have two dimensions: i] authorities need to be more active in market data collection (prices, sales) to allow them to better estimate demand 
conditions and assess whether prices are well above competitive levels. With this respect, authorities may have to develop their own algorithms to resemble market conditions; ii) authorities should also engage in a dialogue with the concerned firms as well as the platforms with which these firms operate in order to find the best possible way to restore consumer welfare. This second dimension follows in spirit the participative antitrust approach proposed by Tirole (2017). It is unrealistic to expect that authorities will be able to get as good information about the market conditions and characteristics as platforms have. Platforms, because of their position in the digital ecosystem, have better chances to detect abnormal pricing behaviour from their external producers that suggest some form of tacit collusion. Even if authorities in the course of evaluating a given case, get access to good quality market data, it will take a large amount of time to understand its implications for the case. In the Google shopping case, the European Commission broke records on the amount of data they collected and processed, but the case itself took more than 7 years for the publication of the decision ${ }^{6}$. So, the approach we propose here requires frequent interaction between authorities and platforms that will lead to mutual recognition and understanding of the firms' strategies that do not reduce consumer welfare. During the COVID-19 pandemic crisis, authorities were working closely with platforms ${ }^{?}$ to identify price gouging practices by online sellers using their services. Such forms of cooperation can continue during normal times to assess excessive, tacit collusive pricing.

A third instrument of competition law is that firms with dominant positions are restricted in the market strategies they can adopt. Since antitrust intervention is ex-post in this case, antitrust has a limited ability to address successfully the associated theories of harm, even if authorities rely more on interim measures.

While the above antitrust measures can be helpful, they are unlikely to be effective without further policy intervention. What we suggest is a regulatory framework that will address the problem ex-ante with respect to the principles of competition law that apply ex-post. Competition policy should be viewed as a measure of last resort that is applied ex-post only when regulation does not have the desired effect.

On the demand side it is important to ensure that multihoming is possible between platforms. A first step to achieve this is to reduce the switching costs and ensure data portability. Experience from banking services can inform how data portability might work. The Open Banking Initiative allows

\footnotetext{
${ }^{6}$ Although, the case did not have to do with a price fixing agreement, it illustrates how difficult it is to collect and analyse data in the frame of a formal antitrust investigation.

? https://www.concurrences.com/pdf version.api/article-93963.pdf.
} 
consumers to obtain, and transmit their banking activity in a standardised and secure fashion to regulated and approved third-party firms in UK (final report from the Stigler Committee on digital platforms, 2019). At the same time, open standards should be encouraged where interoperability between different competing platforms is enforced.

Regulation on the supply side is also crucial. First, transparency needs to be enforced in the platform environment so that external suppliers have access to all the necessary information that they need for their efficient operation on the platform. The European Commission has recently implemented regulation to improve transparency and establish trust in the platform ecosystem. Second, platform access policies should follow the principle of non-discrimination (unless an objective justification of no consumer harm over discriminatory policies in place can be provided] in order to ensure the level playing field between external suppliers and platform's upstream subsidiaries.

As we argued above, data accumulation leads to higher value creation. The challenge we need to address is that it also confers a competitive advantage. Big platforms with large amounts of data generate high value and efficient services. But, that also makes it more difficult for smaller firms to compete with them and provide alternative options to consumers. Ideally, what we want is to both keep value creation at high levels while also encouraging small firms to compete more effectively with high-tech giants. To do that, we need to design data sharing mechanisms that enable small firms to get access to data. In this way, data will not only confer value to the market leaders but also to their competitors, to the benefit of the whole ecosystem. Then we will be able to keep value creation at high levels, while also increasing market competition, contributing to allocative and dynamic efficiency.

The market design for data sharing can be challenging. Fortunately, regulators of financial services like the PSD2 regulation in the EU have created one possible path. PSD2 explicitly empowers account holders with the authority to share data, removing the financial institution's role as gatekeeper. The motivation for this regulation is to reshape the financial sector in a way that small fintech firms have sufficient room to grow and compete with established banking institutions. The incumbents raised the possibility that such regulation would have the unintended consequence of giving preferential access to large technology companies. Applying a similar regulation to other sectors could level the playing field as the issue becomes more evident with the entry of big digital platforms into the financial service sector that do not have to follow PSD2 regulations.

Data sharing should take place without providing incentives for data exploitation. GDPR provides a framework of rules for data sharing, but only in the case that data is related to an identified or 
identifiable person (personal data). In principle, the consent of the user is required. However, according to the Article $6(1)[f]$ of the $G D P R^{8}$, data sharing of personal data can be lawful without user's consent when: "processing is necessary for the purposes of the legitimate interests pursued by the controller or by a third party, except where such interests are overridden by the interests of fundamental rights and freedoms of data subject [user] which require protection of personal data". Namely, a consent is not required in a limited number of cases when the risks of data sharing are small and potential usefulness of data sharing is high. So, with consent or without, the GDPR provides an avenue that facilitates data sharing if that increases consumer welfare (as in our proposal) when privacy risks are low.

It should be noted that anonymised data that is aggregated faces a lower risk of exploitation (Li et al, 2017). While, in principle, the GDPR does not apply to anonymous datasets, research has shown that anonymising individual level personal data in such a way that individuals cannot be re-identified is very difficult, especially, for rich datasets that include multidimensional information (Montjoye et al, 2015). In cases where anonymity becomes a challenge, the employment of methods such as homomorphic encryption or secure multiparty computation can become helpful. Despite these concerns, we expect that the welfare benefits from data sharing are going to be higher than the risks so long as those risks are appropriately managed.

To sum up, the way forward requires both specific innovations in the use of antitrust instruments, as well as a regulatory intervention that will set the necessary standards for facilitating data sharing between competitors. Given the global reach of digital platforms, this approach requires a base level of coordination and collaboration at the international level. To see this, consider the following example: In Europe, antitrust authorities adopt a more dynamic view in merger control, across the lines illustrated above, but US authorities continue to apply the same old-fashioned and ineffective static framework. It is clear that this situation is not ideal for solving the market power issues of digital platforms. Platforms can merge with their potential competitors in the US market and use their increased market power in the US market in a way that provides them with a competitive advantage even in the European market.

So, the proposed updates of antitrust tools require a platform of continuous exchange and coordination between enforcement bodies and legislators. The International Competition Network can be the nexus of coordination between antitrust authorities and practitioners among the countries that are members. Despite its extensive global coverage, some major economies like the Russian

${ }^{8}$ https://www.privacy-regulation.eu/en/article-6-lawfulness-of-processing-GDPR.htm. 
Federation and the People's Republic of China are not members of this body. So, additional discussions should take place between this network and the competition authorities that participate in the BRICs association. Authorities can innovate by adopting practical new techniques in the application of competition law in digital markets and coordinate on studying specific markets through surveys and other tools. In terms of case law and legislative actions, when needed, some further coordination and convergence will be particularly welcome, maybe through extending interaction under the OECD umbrella on these issues.

On our recommendations for data sharing mechanisms, we need to ensure the free flow of data and minimise the cases of data localisation. To achieve this, we need to make sure that strong privacy protection is in place when data transfers take place. A promising avenue can be the bilateral data transfer agreements between different jurisdictions under some common characteristics and principles. For example, the EU-US Privacy Shield dictates that Europeans are protected according to the GDPR standards even when their data is transferred to the US. Similar bilateral agreements have been signed with other countries that wish to have access to data of European citizens. By building on such agreements and expanding their reach, we can solve coordination problems in terms of privacy rules. Consequently, we can design flexible data sharing mechanisms that solve market power problems that go beyond the borders of specific jurisdiction.

While, some base level of coordination across boundaries is important, jurisdictions should also keep their freedom and flexibility to adjust specific rules to their own economic realities and characteristics in a way that does not contradict the basic principles. Besides, we expect that such flexibility will be critical for establishing the necessary common ground. From the lengthy reports published from jurisdictions across the world, we see that they frequently identify the same market competition challenges from the operation of digital platforms. So, why not also adopt, in principle, common solutions?

A potential risk that may threaten this necessary coordination at the global scale is the industrial policy goals of different countries and jurisdictions that are divergent. For example, the US, EU and China are ambitious in their artificial intelligence strategies and are trying to increase their prominence and influence. A particular dimension of this ambition is reflected in the industrial strategies adopted in each of these three jurisdictions. Such strategies try often to influence the way competition policy is applied (recall for example the intensive debate behind the Alstom-Siemens merger case) and made it more lenient to protectionism motives. The new approach we propose here requires both ex-ante regulation as well as ex-post competition policy measures to be applied without any dependence on 
political or industrial policy motives. It is necessary to keep the application of competition principles independent and consider them as the basis for any industrial policies that come into force (see for example Petropoulos, 2019, on the harmonic relationship between competition and industrial policy). Competition policy should not serve any protectionism function. It should serve market efficiency and consumer welfare. Of course, we recognise that suppressing national aspirations for the common good poses diplomatic challenges, but that should not prevent us from establishing common goals.

\section{References}

Adner, Ron, Phanish Puranam, and Feng Zhu (2019) 'What Is Different About Digital Strategy? From Quantitative to Qualitative Change', Strategy Science 4, no. 4: 253-61, https://doi.org/10.1287/stsc.2019.0099

Aghion, P., N. Bloom, R. Blundell, R. Griffith, and P. Howitt (2005) 'Competition and Innovation: an Inverted-U Relationship', The Quarterly Journal of Economics 120, no. 2: 701-28, https://doi.org/10.1093/qje/120.2.701

Akerlof, George A. "The Market for 'Lemons': Quality Uncertainty and the Market Mechanism." The Quarterly Journal of Economics 84, no. 3 (1970): 488. https://doi.org/10.2307/1879431

Anderson, R. (2001) 'Why Information Security Is Hard - an Economic Perspective', Seventeenth Annual Computer Security Applications Conference, https://doi.org/10.1109/acsac.2001.991552

Armstrong, Mark (2006) 'Competition in Two-Sided Markets', The RAND Journal of Economics 37, no. 3: 668-91, https://doi.org/10.1111/j.1756-2171.2006.tb00037.x

Arrow, Kenneth J. (1962) 'Economic Welfare and the Allocation of Resources for Invention', The Rate and Direction of Inventive Activity, 609-26, https://doi.org/10.1515/9781400879762-024

Autor, David, David Dorn, Lawrence F Katz, Christina Patterson, and John Van Reenen (2020) 'The Fall of the Labor Share and the Rise of Superstar Firms*', The Quarterly Journal of Economics, March, https://doi.org/10.1093/qje/qjaa004

Bakos, Yannis and Hanna Halaburda (2020) 'Platform Competition with Multi-Homing on Both Sides: Subsidize or Not?" CESifo Working Paper No. 8126, https://ssrn.com/abstract=3545723

Bajari, Patrick, Victor Chernozhukov, Ali Hortaçsu, and Junichi Suzuki [2019] 'The Impact of Big Data on Firm Performance: An Empirical Investigation', AEA Papers and Proceedings 109: 33-37, https://doi.org/10.125?/pandp.20191000

Barefoot, Kevin, Dave Curtis, William Jollif, Jessica Nicholson, Robert Omohundro (2019) 'Measuring the Digital Economy', Bureau of Economic Analysis technical report, accessed 5 May 2020, https://apps.bea.gov/scb/2019/05-may/0519-digital-economy.htm 
Belleflamme, Paul, and Martin Peitz (2019) 'Platform Competition: Who Benefits from Multihoming?" International Journal of Industrial Organization 64: 1-26,

https://doi.org/10.1016/j.jindorg.2018.03.014

Benzell Seth G. and Avinash Collis (2019) 'Multi-Sided Platform Strategy, Taxation, and Regulation: A Quantitative Model and Application to Facebook', mimeo

Borenstein, Severin, and Nancy L. Rose (1994) 'Competition and Price Dispersion in the U.S. Airline Industry', Journal of Political Economy 102, no. 4: 653-83, https://doi.org/10.1086/261950

Brynjolfsson Erik and Avinash Collis (2019) 'How should we measure the digital economy?' Harvard Business Review

Brynjolfsson, Erik, Avinash Collis, W. Erwin Diewert, Felix Eggers, and Kevin Fox [2019] 'GDP-B:

Accounting for the Value of New and Free Goods in the Digital Economy',

https://doi.org/10.3386/w25695

Calligaris, Sara, Chiara Criscuolo, and Luca Marcolin (2018) 'Mark-Ups in the Digital Era', OECD Science, Technology and Industry Working Papers, https://doi.org/10.1787/4efe2d25-en

Calvano, Emilio, Giacomo Calzolari, Vincenzo Denicolo, and Sergio Pastorello [2018) 'Artificial Intelligence, Algorithmic Pricing and Collusion', SSRN Electronic Journal, https://doi.org/10.2139/ssrn.3304991

Constantinides, Panos, Ola Henfridsson, and Geoffrey G. Parker (2018) 'Introduction-Platforms and Infrastructures in the Digital Age', Information Systems Research 29, no. 2: 381-400, https://doi.org/10.1287/isre.2018.0794

David, Paul A. (1985) 'Clio and the Economics of QWERTY', The American Economic Review, 75.2: 332337

Diez, Federico, Daniel Leigh, and Suchanan Tambunlertchai (2018) 'Global Market Power and Its Macroeconomic Implications', IMF Working Papers 18, no. 137: 1, https://doi.org/10.5089/9781484361672.001

Economides, Nicholas and loannis Lianos (2019) 'Restrictions on Privacy and Exploitation in the Digital Economy: A Competition Law Perspective', NET Institute. Working Paper \#19-15

Edelman, Benjamin, and Julian Wright (2015) 'Price Coherence and Excessive Intermediation*', The Quarterly Journal of Economics 130, no. 3: 1283-1328, https://doi.org/10.1093/qje/qjv018

European Commission [2017] 'Final report on the E-commerce Sector Inquiry', SWD [2017) 154 final

European Commission (2018) 'Impact Assessment Accompanying the document Proposal for a Regulation of the European Parliament and of the Council on promoting fairness and transparency for business users of online intermediation services', COM [2018) 238 final

Ezrachi, Ariel (2015) 'The Competitive Effects of Parity Clauses on Online Commerce', European Competition Journal 11, no. 2-3 (February): 488-519, https://doi.org/10.1080/17441056.2016.1148870 
Ezrachi, Ariel, and Maurice E. Stucke (2016) Virtual Competition: The Promise and Perils of the Algorithm-Driven Economy, Harvard University Press, https://doi.org/10.4159/9780674973336

Friedman, James W. (1971) 'A Non-Cooperative Equilibrium for Supergames', The Review of Economic Studies 38, no. 1: 1. https://doi.org/10.2307/229661?

Gantz, John, and David Reinsel (2011) ‘Extracting Value from Chaos', International Data Corporation (IDC) View

Gawer, Annabelle, and Michael A. Cusumano (2002) Platform leadership: How Intel, Microsoft, and Cisco drive industry innovation, Boston, MA: Harvard Business School Press

Gutiérrez, Germán, and Thomas Philippon (2017) 'Declining Competition and Investment in the U.S.', https://doi.org/10.3386/w23583

Hagiu, Andrei, and Julian Wright (2015) 'Multi-Sided Platforms', International Journal of Industrial Organization 43: 162-74, https://doi.org/10.1016/j.jijindorg.2015.03.003

Hall, Robert (2018) 'Using Empirical Marginal Cost to Measure Market Power in the US Economy', https://doi.org/10.3386/w25251

Hesse, Renata B. (2007) 'Two-sided platform markets and the application of the traditional antitrust analytical framework', Competition Policy International 3.1

Kamepalli, Sai Krishna, Rajan, Raghuram G. and Luigi Zingales (2020) 'Kill Zone', University of Chicago, Becker Friedman Institute for Economics Working Paper No. 2020-19, https://ssrn.com/abstract=3555915 or http://dx.doi.org/10.2139/ssrn.3555915

Katz, Michael L., and Carl Shapiro (1985) 'Network externalities, competition, and compatibility', The American Economic Review 75.3: 424-440

Kwoka, John E., and Lawrence J. White (1999) The Antitrust Revolution: Economics, Competition, and Policy, New York: Oxford University Press

Li, Ninghui, Tiancheng Li, and Suresh Venkatasubramanian (2007) 't-Closeness: Privacy Beyond kAnonymity and I-Diversity', IEEE 23rd International Conference on Data Engineering, https://doi.org/10.1109/icde.2007.367856

Loecker, Jan De, Jan Eeckhout, and Gabriel Unger (2020) 'The Rise of Market Power and the Macroeconomic Implications', The Quarterly Journal of Economics, https://doi.org/10.1093/qje/qjz041

McAfee, A., and E. Brynjolfsson (2008) 'Investing in the ICT That Makes a Competitive Difference', Harvard Business Review, Vol. 86 No. 7/8: 98-107

Montjoye, Y.-A. De, L. Radaelli, V. K. Singh, and A. S. Pentland (2015) 'Unique in the Shopping Mall: On the Reidentifiability of Credit Card Metadata', Science 347, no. 6221: 536-39, https://doi.org/10.1126/science.125629?

OECD [2014] 'Data-Driven Innovation for Growth and Well-Being', Interim Synthesis Report, Organisation for Economic Cooperation and Development 
Parker, Geoffrey G., Georgios Petropoulos and Marshall W. Van Alstyne (2020) 'Digital Platforms, Market Power and Antitrust: A proposal towards efficient data sharing mechanisms', mimeo

Parker, Geoffrey G., and Marshall W. Van Alstyne (2005) 'Two-Sided Network Effects: A Theory of Information Product Design', Management Science 51, no. 10: 1494-1504, https://doi.org/10.1287/mnsc.1050.0400

Parker, Geoffrey, and Marshall Van Alstyne (2018) 'Innovation, Openness, and Platform Control', Management Science 64, no. 7: 3015-32, https://doi.org/10.1287/mnsc.2017.275?

Parker, Geoffrey, Marshall Van Alstyne, and Sangeet Paul. Choudary [2016] Platform Revolution: How Networked Markets Are Transforming the Economy and How to Make Them Work for You. New York: W.W. Norton \& Company

Parker, Geoffrey, Marshall Van Alstyne, and Xiaoyue Jiang (2017) ‘Platform Ecosystems: How Developers Invert the Firm', MIS Quarterly 41, no. 1 (January): 255-66, https://doi.org/10.25300/misq/2017/41.1.13

Petropoulos, Georgios (2019) 'How should the relationship between competition policy and industrial policy evolve in the European Union?' Bruegel Blog, 15 July, available at https://www.bruegel.org/2019/07/how-should-the-relationship-between-competition-policy-andindustrial-policy-evolve-in-the-european-union/

Petropoulos, Georgios (2018) 'Vertical restraints and e-commerce', Concurrences Review $\mathrm{N}^{0} 1$, Art. № 86057

Philippon, Thomas [2019] The Great Reversal: How America Gave up on Free Markets. Cambridge, MA: The Belknap Press of Harvard University Press

Rochet, Jean-Charles, and Jean Tirole (2003) 'Platform Competition in Two-Sided Markets', Journal of the European Economic Association 1, no. 4 (January): 990-1029, https://doi.org/10.1162/154247603322493212

Rysman, Marc (2009) 'The Economics of Two-Sided Markets', Journal of Economic Perspectives 23, no. 3: 125-43, https://doi.org/10.125?/jep.23.3.125

Schaefer, Maximilian, Geza Sapi, and Szabolcs Lorincz (2018) 'The Effect of Big Data on Recommendation Quality: The Example of Internet Search', SSRN Electronic Journal, https://doi.org/10.2139/ssrn.3161325

Schumpeter, Joseph Alois (1934) The Theory of Economic Development: an Inquiry into Profits, Capital, Credit, Interest, and the Business Cycle, Harvard University Press

Shapiro, Carl, and Hal R. Varian (1998) Information Rules: a Strategic Guide to the Network Economy. Boston, MA: Harvard Business School Press

Steinbaum, Marshall, and Maurice E. Stucke (2020) 'The Effective Competition Standard: A New Standard for Antitrust', University of Chicago Law Review

Stigler Committee on Digital Platforms (2019) Final report 
Stucke, Maurice E., and Allen P. Grunes (2016) Big Data and Competition Policy, Oxford: Oxford University Press

Tirole, Jean, and Steven Rendall [2017) Economics for the Common Good, Princeton: Princeton University Press

Traina, James (2018) 'Is Aggregate Market Power Increasing? Production Trends Using Financial Statements', SSRN Electronic Journal, https://doi.org/10.2139/ssrn.3120849

UK Digital Competition Expert Panel (2019) Final Report

Varian, Hal R., Joseph Farrell, and Carl Shapiro [2004] The Economics of Information Technology: An Introduction, Cambridge: Cambridge Univ. Press

Von Hayek, Friedrich August [1945] 'The use of knowledge in society', The American Economic Review 35.4: 519-530

Whittington, J. and C.J. Hoofnagle (2012) 'Unpacking Privacy's Price', 90 North Carolina Law Review 1327

Williamson, Oliver E. (1973) 'Markets and hierarchies: some elementary considerations', The American Economic Review 63.2: 316-325 
(c) Bruegel 2020. All rights reserved. Short sections, not to exceed two paragraphs, may be quoted in the original language without explicit permission provided that the source is acknowledged. Opinions expressed in this publication are those of the author[s] alone.

Bruegel, Rue de la Charité 33, B-1210 Brussels

$(+32) 22274210$

info@bruegel.org

bruegel

www.bruegel.org 